\title{
Article \\ On the Electroanalytical Detection of Zn Ions by a Novel Schiff Base Ligand-SPCE Sensor
}

\author{
Viviana Bressi ${ }^{1}$, Zahra Akbari ${ }^{1,2}$, Morteza Montazerozohori ${ }^{2}{ }^{\oplus}$, Angelo Ferlazzo ${ }^{1}$, Daniela Iannazzo ${ }^{1}(\mathbb{D}$, \\ Claudia Espro ${ }^{1, *(1)}$ and Giovanni Neri ${ }^{1, *(D)}$ \\ 1 Department of Engineering, University of Messina, I-98166 Messina, Italy; vibressi@unime.it (V.B.); \\ zakbari@unime.it (Z.A.); angelo.ferlazzo@unime.it (A.F.); daniela.iannazzo@unime.it (D.I.) \\ 2 Department of Chemistry, Yasouj University, Yasouj 7591874831, Iran; mmzohori@mail.yu.ac.ir \\ * Correspondence: espro@unime.it (C.E.); gneri@unime.it (G.N.)
}

check for updates

Citation: Bressi, V.; Akbari, Z.;

Montazerozohori, M.; Ferlazzo, A.; Iannazzo, D.; Espro, C.; Neri, G. On the Electroanalytical Detection of $\mathrm{Zn}$ Ions by a Novel Schiff Base

Ligand-SPCE Sensor. Sensors 2022, 22, 900. https://doi.org/10.3390/

s22030900

Academic Editor: Katarzyna

Tyszczuk-Rotko

Received: 20 December 2021

Accepted: 20 January 2022

Published: 25 January 2022

Publisher's Note: MDPI stays neutral with regard to jurisdictional claims in published maps and institutional affiliations.

Copyright: (C) 2022 by the authors. Licensee MDPI, Basel, Switzerland. This article is an open access article distributed under the terms and conditions of the Creative Commons Attribution (CC BY) license (https:// creativecommons.org/licenses/by/ $4.0 /)$.

\begin{abstract}
A novel bidentate Schiff base (L) is here proposed for the detection of $\mathrm{Zn}$ ions in water. The structure of the synthesized Schiff base L was characterized by FT-IR, ${ }^{1} \mathrm{H}$ NMR and ${ }^{13} \mathrm{C}$ NMR. Optical characteristics were addressed by UV-Visible spectroscopy and Photoluminescence (PL) measurements. PL demonstrated that L displays a "turn-off" type fluorescence quenching in the presence of $\mathrm{Zn}^{2+}$ ion in aqueous solution, indicating its ability to preferentially coordinate this ion. Based on these findings, an L-M (where $\mathrm{M}$ is a suitable membrane) modified screen-printed carbon electrode (SPCE) was developed to evaluate the electrochemical behavior of the Schiff base (L) with the final objective of undertaking the electroanalytical determination of $\mathrm{Zn}$ ions in water. Using various electrochemical techniques, the modified L-M/SPCE sensor demonstrates high sensitivity and selectivity to $\mathrm{Zn}$ ions over some common interferents ions, such as $\mathrm{Ca}^{2+}, \mathrm{Mg}^{2+}, \mathrm{K}^{+}, \mathrm{Ni}^{++}$and $\mathrm{Cd}^{++}$. The potentiometric response of the L-M/SPCE sensor to $\mathrm{Zn}$ ions was found to be linear over a relatively wide concentration range from $1 \mu \mathrm{M}$ to $100 \mathrm{mM}$.
\end{abstract}

Keywords: Schiff base; fluorescence; electrochemical sensors; heavy metals; trace analysis of pollutants and contaminants

\section{Introduction}

Schiff base ligands have been known about for a very long time and can be easily synthesized by condensation reactions of primary amines and carbonyl compounds in which the characteristic azomethine bond is formed [1]. Interest in Schiff bases has rapidly grown, and they played a central role in the development of coordination chemistry due to their unique properties, including high stability and selectivity to metal coordination, good reproducibility, more active sites and good homogeneity, making them particularly attractive in the field of metal ion recognition, especially by means of optical techniques [2-4].

In recent decades, electrochemical sensors have received great attention due to their good versatility in heavy metal ion detection. Several Schiff bases have been used in the development of innovative electrodes for the electrochemical recognition of heavy metal ions in water [5-7].

The greatest interest now relates to heavy metals such as lead, mercury, and cadmium, which even at very low concentrations can be harmful to human health. These metals are introduced into the aquatic ecosystem and the soil because of the erosion of rocks, volcanic eruptions, or by multiple human activities, such as production of industrial waste. Among the various heavy metal ions, $\mathrm{Zn}^{2+}$ plays an important role in the regulation of many reactions catalyzed by enzymes in the human body and therefore maintains physiological processes at the optimal level. Zinc is considered as an essential trace element for human beings due to its relationship with insulin production [8,9], and for the regulation of biological processes, being involved as catalysts for more than 200 enzymes [10]. In addition, 
zinc is also present in food, e.g., proteins that are high in zinc content. Although $\mathrm{Zn}^{2+}$ is considered relatively non-toxic, at high concentration, symptoms of toxicity can manifest such as nausea, vomiting, lethargy and fatigue [11]. Recent studies have shown that the possible alteration of serum levels of $\mathrm{Zn}^{2+}$ is related to the development of neurodegenerative pathologies, in particular, Alzheimer's disease [12,13]. This cation is also presents in waste products from different industries such as paint, electroplating, pharmaceutical, and fine chemical manufacturing. For this reason, zinc ion detection is highly demanded.

Conventional methods employed for contaminant monitoring suffer from several drawbacks, requiring expensive devices and complex sample handling, in addition to being time-consuming and highly destructive [14]. Among the several kinds of electrodes, mercury-based electrodes have been traditionally used in the stripping techniques due to their high sensitivity. Hence, they have widely been accepted as the most sensitive electrodes for the determination of heavy metals. Moreover, different electrochemical techniques have been used to detect and measure $\mathrm{Zn}$ ions using mercury-based electrodes [15-18].

However, the use of these techniques has tended to decrease because the use of mercury affects the environment. As the use of mercury becomes increasingly restricted by health and safety regulations, the development of electrochemical approaches with high selectivity and sensitivity for zinc, that do not involve the use of mercury-based electrodes, is currently of great interest as they allow prompt detection of metal ions by simple responses. In particular, the development of electrochemical sensors that can discriminate $\mathrm{Zn}^{2+}$ from the elements of the same group of the periodic table with similar properties is still a challenge. Our approach fits into this scientific and technological context with the aims to identify and develop an innovative electrochemical method for the determination of zinc, by using a screen-printed electrode modified with a novel bidentate Schiff base named $\mathrm{L}$. The synthesis and complexation of the base Schiff ligand $\mathrm{L}$ for preparing $\mathrm{ZnL}$ complexes and their sensing properties have been reported in a previous work [19]. Considering the peculiar characteristics of this Schiff base, we initiated a study to investigate this ligand as a sensing element for developing a new electrochemical sensor for $\mathrm{Zn}$ ions.

\section{Materials and Methods}

\subsection{Chemicals}

Starting reagents for the synthesis of Schiff base ligand L were purchased from commercial suppliers (Sigma-Aldrich Handels Gmbh, Overijse, Belgium) in high purity and used without further purification. Standard solution of $\mathrm{Zn}^{2+}$ was prepared by dissolving zinc (II) nitrate hexahydrate $(0.0297 \mathrm{gr}, 10 \mathrm{mM})$ in $10 \mathrm{~mL}$ of double distilled water. Similarly, all the stock solution was prepared using nitrate salts of respective cations and dissolving them in double distilled water. All chemicals were extra pure analytical grade.

\subsection{Synthesis of Bidentate Schiff Base Ligand ( $L$ )}

The Schiff base L (whose chemical name is: N1,N3-bis((E)-3-(4-methoxyphenyl)allylidene)2,2-dimethylpropane-1,3-diamine) was synthesized under ultrasonic irradiation as follows. An ethanolic solution of 2,2-dimethylpropane-1,3-diamine (1 mmol in $10 \mathrm{~mL})$ was drop-wise added to an ethanolic solution of (E)-3-(4-methoxyphenyl) acrylaldehyde $(2 \mathrm{mmol}$ in $10 \mathrm{~mL}$ ). The reaction progress was monitored by TLC. After completion of the condensation reaction $(30 \mathrm{~min})$, the product was obtained as a milky precipitate. After evaporation of solvent, the ligand was obtained. Yield: $49 \%$. m.p: $149-151^{\circ} \mathrm{C}$. UV-Vis in DMF [ $\left.\lambda \max ; \mathrm{nm}\left(\lambda ; \mathrm{cm}^{-1} \mathrm{M}^{-1}\right)\right]$ : $318(99,164), 380(70,958)$. Molar conductivities in DMF $\left[\Lambda^{\circ} \mathrm{M} ; \mathrm{cm}^{2} \Omega^{-1} \mathrm{~mol}^{-1}\right]$ ]: 1.12. Selected FT-IR data $\left(\mathrm{KBr}, \mathrm{cm}^{-1}\right): 3058(\vee \mathrm{C}-\mathrm{H}$ aromatic), 3014 ( $\vee$ C-H alkenic), 2965 ( $\vee$ C-H aliphatic), 2868 ( $\vee$ C-H iminic), $1632(\vee \mathrm{C}=\mathrm{N}), 1462(\vee \mathrm{C}=\mathrm{C})$, $1171(\vee \mathrm{C}-\mathrm{N})$. 1H NMR (DMSO-d6): [ $\delta$; ppm]: 8.02(s, 2Hc, $\left.\mathrm{c}^{\prime}, \mathrm{J}=8.7 \mathrm{~Hz}\right), 7.57\left(\mathrm{~d}, 4 \mathrm{Hf}, \mathrm{f}^{\prime}\right.$, $\mathrm{J}=8.87 \mathrm{~Hz}), 7.03\left(\mathrm{~d}, 2 \mathrm{He}, \mathrm{e}^{\prime}, \mathrm{J}=16.0 \mathrm{~Hz}\right), 6.97\left(\mathrm{~d}, 4 \mathrm{Hg}, \mathrm{g}^{\prime}, \mathrm{J}=8.8 \mathrm{~Hz}\right), 6.85\left(\mathrm{dd}, 2 \mathrm{Hd}, \mathrm{d}^{\prime}\right.$, $\mathrm{J} 1=16.0 \mathrm{~Hz}$ and, $\mathrm{J} 2=8.7 \mathrm{~Hz}), 3.80\left(\mathrm{~s}, 6 \mathrm{Hh}, \mathrm{h}^{\prime}\right), 3.35\left(\mathrm{~s}, 4 \mathrm{Hb}, \mathrm{b}^{\prime}\right), 0.92\left(\mathrm{~s}, 6 \mathrm{Ha}, \mathrm{a}^{\prime}\right) \mathrm{ppm} .13 \mathrm{C} \mathrm{NMR}$ 
(DMSO-d6): $163.57\left(\mathrm{C} 4,4^{\prime}\right), 160.48\left(\mathrm{C} 10,10^{\prime}\right), 141.46\left(\mathrm{C} 6,6^{\prime}\right), 129.26\left(\mathrm{C} 8,8^{\prime}\right), 128.79\left(\mathrm{C} 7,7^{\prime}\right)$, $126.42\left(\mathrm{C} 9,9^{\prime}\right), 114.76\left(\mathrm{C} 5,5^{\prime}\right), 70.40\left(\mathrm{C} 3,3^{\prime}\right), 55.69\left(\mathrm{C} 11,11^{\prime}\right), 37.00\left(\mathrm{C} 1,1^{\prime}\right), 24.79\left(\mathrm{C} 2,2^{\prime}\right) \mathrm{ppm}$.

\subsection{Characterization}

The FT-IR spectra (as KBr disks, $4000-400 \mathrm{~cm}^{-1}$ ) were recorded using a JASCO-460 instrument with scanning speed of $2 \mathrm{~mm} / \mathrm{s}$, resolution $4 \mathrm{~cm}^{-1}$, accumulation of 25 and gain of 2 . The electronic spectrum of the Schiff base ligand was measured in dimethylformamide (DMF) solvent at ambient temperature and in the range of $200-800 \mathrm{~nm}$ by a JASCO-V570 spectrophotometer instrument. ${ }^{1} \mathrm{H}$ and ${ }^{13} \mathrm{C}$ NMR spectra were recorded in DMSO- $\mathrm{d}_{6}$ (deuterated dimethylsulfoxide) as solvent and tetra methylsilane as internal standard using a Brucker DPX FT/NMR-300 MHz spectrometer.

Fluorescence measurements were performed using a NanoLog modular (Horiba) spectrofluorometer equipped with glass cuvettes $(1 \mathrm{~cm}$ path length). Emission spectra were recorded under excitation with a Xenon lamp at a fixed wavelength of excitation $(\lambda: 340 \mathrm{~nm})$ and slit 9 . L solution was prepared as described above and the addition of zinc ion was carried out directly in the solution. Moreover, changes in fluorescence intensities vs. time appear immediately (and after $15 \mathrm{~min}$ ). However, the fluorescence intensity of $\mathrm{L}$ decreases immediately and does not undergo any variation in the following times, demonstrating that the complex with the zinc ion is formed.

\subsection{Electrochemical Tests}

Electrochemical measurements were performed using a commercial SPCE, comprising a planar substrate equipped with a $4 \mathrm{~mm}$ carbon working-electrode (geometric area, $0.1257 \mathrm{~cm}^{2}$ ), a silver pseudo-reference electrode and a carbon auxiliary electrode. Cyclic voltammetry $(\mathrm{CV})$ and potentiometric measurements were performed using a DropSens $\mu$ Stat 400 Potentiostat powered by Dropview 8400 software for data acquisition.

Bare screen-printed carbon electrodes (SPCEs) were easily modified as follows. A quantity of $1.0 \mathrm{mg}$ of $\mathrm{L}$ was ultrasonically dissolved in $0.5 \mathrm{~mL}$ of DMSO. Thereafter, $2 \mu \mathrm{L}$ of the solution was directly dropped onto the surface of the carbon working electrode and were allowed to dry at room temperature until further use.

Moreover, a L-M/SPCE sensor was obtained by mixing the Schiff base ligand with a conductive membrane $(\mathrm{M})$. The membrane was prepared by mixing $0.5 \mathrm{mg}$ of sodium tetraphenylborate (NaTBP), $33 \mathrm{mg}$ of polyvinylchloride (PVC), $65.71 \mathrm{mg}$ of 2-nitrophenyloctylether (2-NPOE) and $1 \mathrm{mg}$ of $\mathrm{L}$. The components were dissolved in $1.0 \mathrm{~mL}$ of THF and $2 \mu \mathrm{L}$ of the mixture was deposited on the sensor. The solvent was allowed to dry overnight at room temperature to obtain a transparent membrane.

Linear sweep voltammetry (LSV) and potentiometric calibration curves using SPCE were performed by adding small volumes of the metal ions stock standard solutions into the electrochemical cell containing $3 \mathrm{~mL}$ of distilled water. Three scans were made for each new unit in buffer solution before taking reliable measurements to stabilize the SPCEs. To ensure the elimination of the metal ions from the working SPCE surface, a conditioning potential at $1.3 \mathrm{~V}$ for $30 \mathrm{~s}$ was applied before each measurement. All experiments were carried out without any oxygen elimination and at room temperature $\left(25^{\circ} \mathrm{C}\right)$.

\section{Results}

\subsection{Characterization of Schiff Base Ligand}

A schematic representation of the L ligand is shown in Scheme 1. Data related to FT-IR, NMR, UV-Vis spectra and molar conductivities of Schiff base ligand $L$ were described in previous Section 2. 


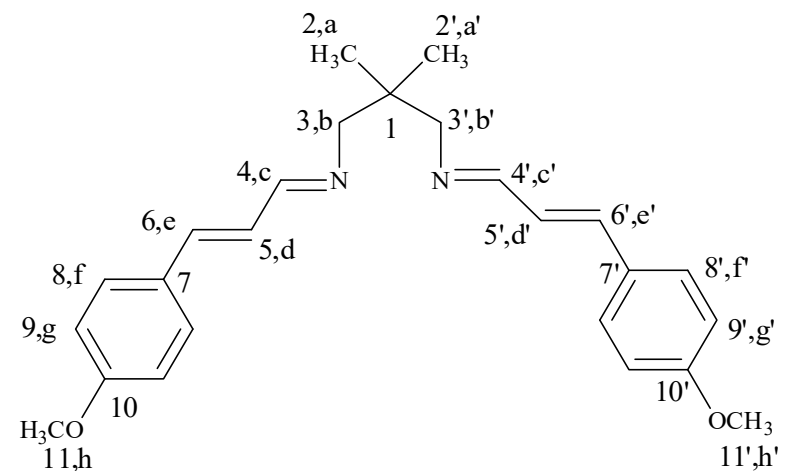

Scheme 1. Atom numbering representation of Schiff base ligand L.

FT-IR spectroscopy is the first and easiest step to identify novel synthetic compounds via functional groups. Figure 1 shows the IR spectrum of the Schiff base ligand L. Compared to the expected bands related to reactants, the lack of stretching vibrations of $\mathrm{NH}_{2}$ of primary amine at $3285 \mathrm{~cm}^{-1}$ and $\mathrm{C}=\mathrm{O}$ of 4-methoxycinnamaldehade at $1685 \mathrm{~cm}^{-1}$ as initial reactants, and the appearance of a new sharp and strong peak at $1632 \mathrm{~cm}^{-1}$ indicating formation of azomethine or iminic $(C=N)$ bond as a characteristic functional agent of the Schiff base compounds, support the idea that the titled Schiff base ligand was successfully synthesized. Moreover, the weak vibrations at 3058 and $2965 \mathrm{~cm}^{-1}$ are assigned to the stretching vibrations of $\mathrm{C}-\mathrm{H}$ bonds of aromatic and aliphatic fragments, respectively. Further bands between 2900 and $2800 \mathrm{~cm}^{-1}$ are associated with the stretching vibrations of the aliphatic $\mathrm{C}-\mathrm{H}$ groups, whereas $\mathrm{C}-\mathrm{H}$ bending of the methyl group appears at $1400 \mathrm{~cm}^{-1}$. Finally, the strong band at $1275-1200 \mathrm{~cm}^{-1}$ is due to C-O stretching of aryl ether.

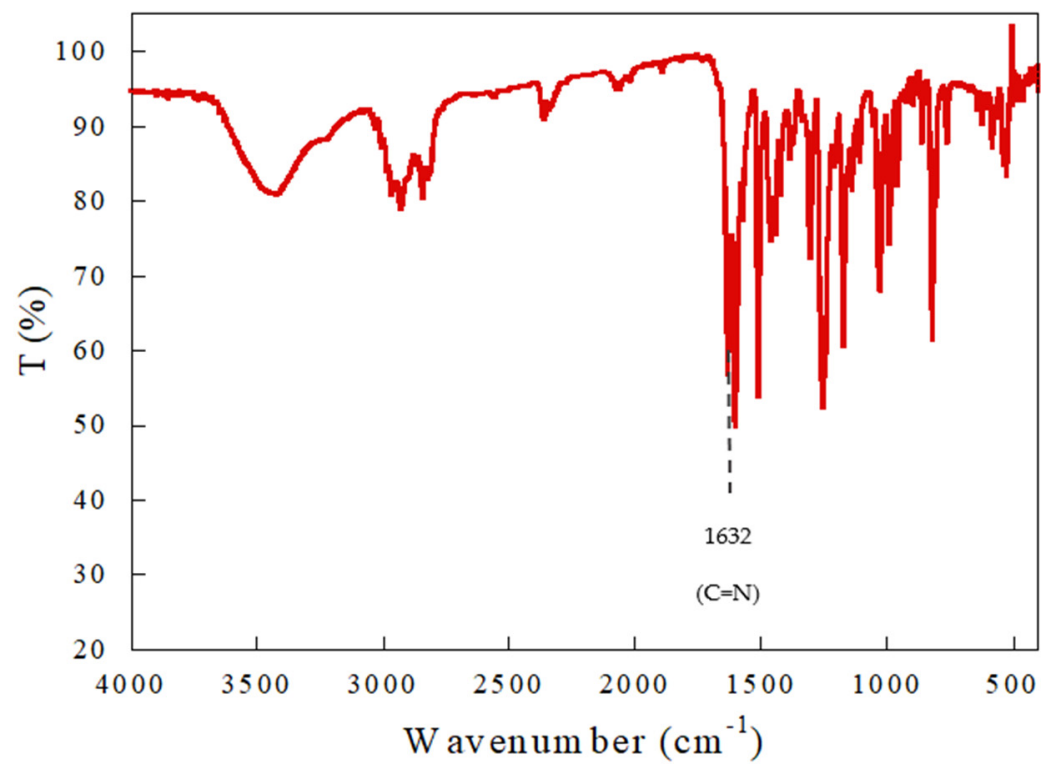

Figure 1. FT/IR spectrum of ligand L.

${ }^{1} \mathrm{H}$ NMR and ${ }^{13} \mathrm{C}$ NMR spectra of ligand(L) based on Scheme 1 are exhibited in Figure 2. In the ${ }^{1} \mathrm{H}$ NMR spectrum of the ligand, azomethine hydrogens of $\mathbf{c c}^{\prime}$ are observed at $8.02 \mathrm{ppm}$ as a doublet signal with coupling constant of $8.7 \mathrm{~Hz}$. Olefinic hydrogens of $\mathbf{e e}^{\prime}$ and $\mathbf{d d}^{\prime}$ in the ligand spectrum appear at 7.03 and $6.85 \mathrm{ppm}$ as doublet and doublet of doublet, respectively. Aromatic hydrogens of $\mathbf{g g}^{\prime}$ and $\mathbf{f f}^{\prime}$ in the ligand spectrum are seen at 6.97 and 7.57 ppm as doublet peaks. Aliphatic hydrogens of $\mathbf{a a}^{\prime}, \mathbf{b b}^{\prime}$ and $\mathbf{h} \mathbf{h}^{\prime}$ in the ligand appear at $0.92,3.35$ and 3.80 ppm as singlet peaks, respectively. In the ${ }^{13} \mathrm{C} \mathrm{NMR}$ spectrum of ligand L, the characteristic signal is related to azomethine carbon appearing at 
$163.57 \mathrm{ppm}$. Aromatic, olefinic and aliphatic carbons of ligand L appear at 126.42-160.48, 114.76-141.46 and 24.79-70.40 ppm, respectively.

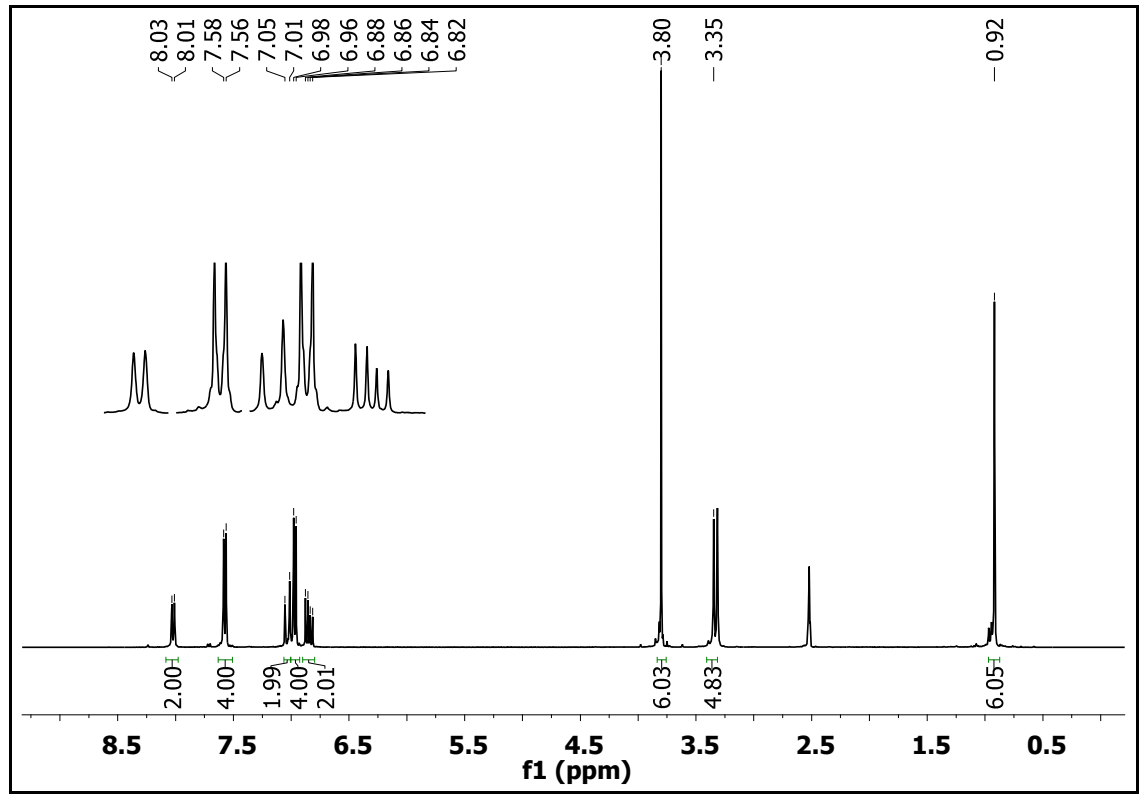

(a)

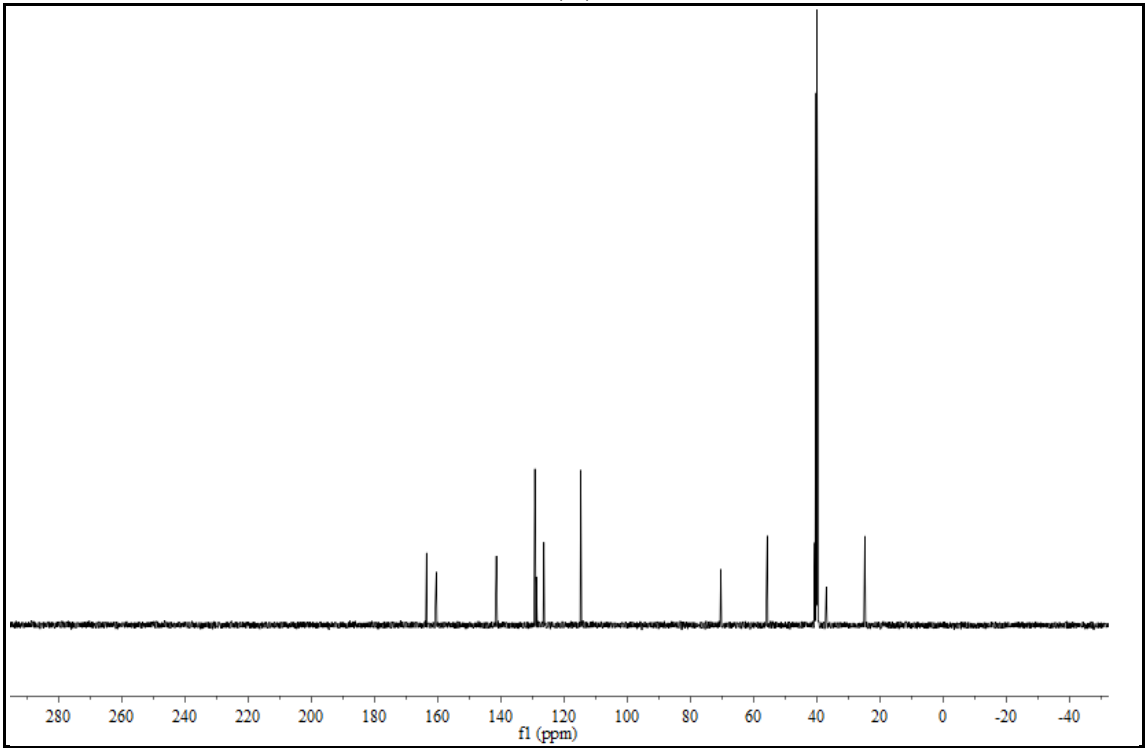

(b)

Figure 2. (a) ${ }^{1} \mathrm{H}$ NMR spectra of ligand (L) and (b) 13C NMR spectra of ligand L.

Electronic spectrum of $\mathrm{L}$ in the DMF solution $\left(10^{-5} \mathrm{M}\right)$ was recorded in the range of $200-800 \mathrm{~nm}$ at room temperature and the relevant information is found in Figure 3. In the UV- visible spectrum of the ligand, two intense absorption bands were observed. The first band appeared at $318 \mathrm{~nm}$ and is attributed to $\pi \rightarrow \pi^{*}$ electronic transitions of the ligand (aromatic rings and alkene moiety). The second absorption band of the ligand at $380 \mathrm{~nm}$ may be attributed to $\mathrm{n} \rightarrow \pi^{*} / \pi \rightarrow \pi^{*}$ of imine groups. 


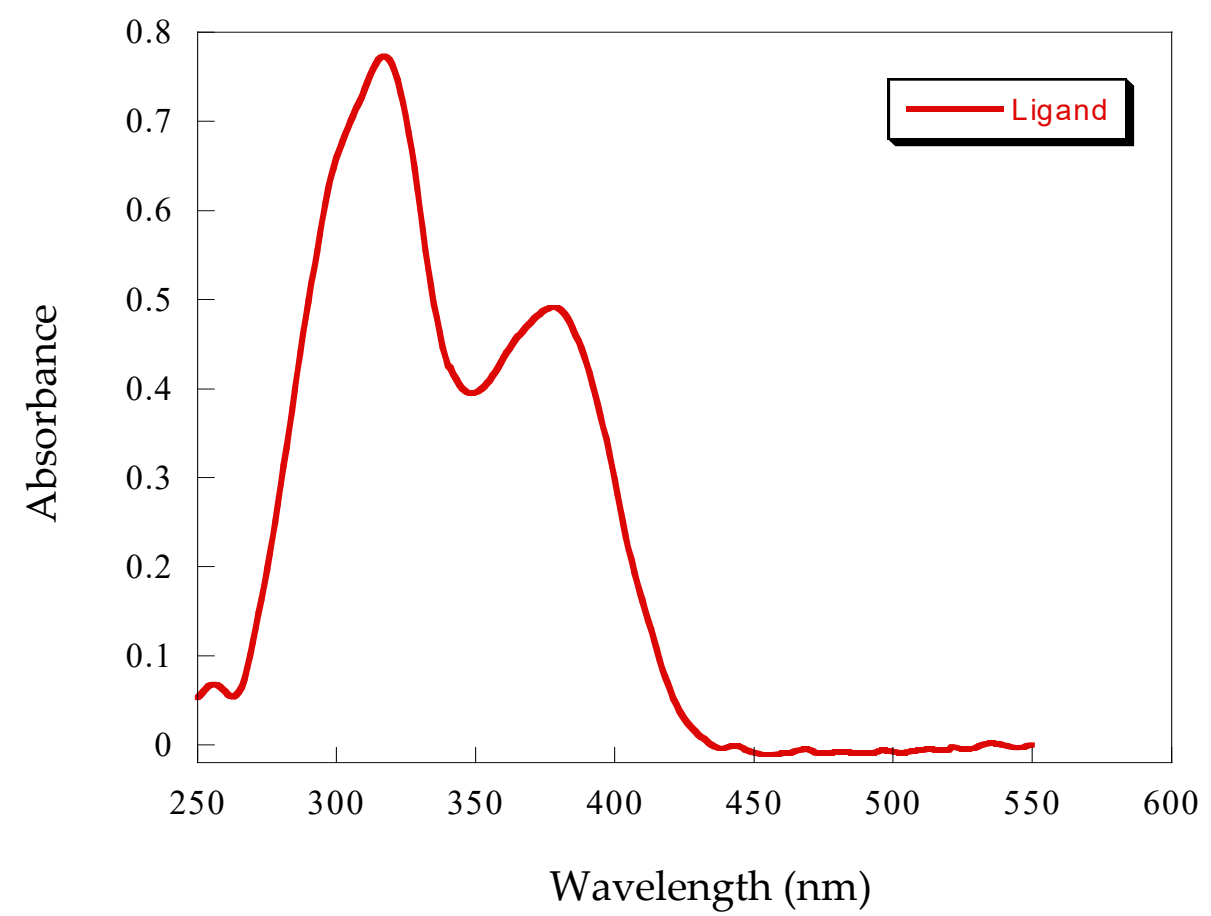

Figure 3. UV-Vis spectrum of the Schiff base ligand L.

\subsection{Fluorescence Studies}

Schiff bases are known to exhibit fluorescence characteristics in both solution and a solid state. The fluorescence from $\mathrm{L}$ in the visible region (see Figure $4 \mathrm{a}$ ) can be explained by the presence of the extended conjugation. At the excitation length of $340 \mathrm{~nm}$, the base shows a fluorescent emission behavior with a well-defined band at $435 \mathrm{~nm}$.

Schiff bases display versatile coordination chemistry with transition metal ions due to the preferred coordinative interaction with the imine $-\mathrm{N}$ and $-\mathrm{OH}$ groups; therefore, in recent years, Schiff bases have been investigated for the detection of various toxic metal ions $[20,21]$. Depending on the ligands and the metal ion, fluorescence tuning both in intensity and/or emission maximum can be observed. A fluorescence enhancement [22] or reduction (fluorescence quenching [23]) can occur upon metal ion coordination.

Investigating the PL properties of L, we found that the addition of $\mathrm{Zn}$ ions caused remarkable changes in the PL peak intensity (Figure $4 \mathrm{~b}$ ). The interaction between $\mathrm{Zn}$ ion and the L Schiff base is assumed to transfer energy to $\mathrm{Zn}(\mathrm{II})$ and hinder the ligand-centered emission, resulting in the luminescent quenching of L [24]. The inset in Figure $4 \mathrm{~b}$ shows the analysis of data on the basis of the Stern-Volmer $\mathrm{I} / \mathrm{I}_{\mathrm{O}}=1+\mathrm{K}_{\mathrm{sv}}\left[\mathrm{Zn}^{2+}\right]$ equation, where $I$ and $I_{0}$ are the fluorescence intensities of the $\mathrm{L}$ solution in the presence and absence of $\mathrm{Zn}$ ions, $\mathrm{K}_{\mathrm{sv}}$ is the Stern-Volmer constant, and $\left[\mathrm{Zn}^{2+}\right]$ the $\mathrm{Zn}$ ions concentration. The $\mathrm{K}_{\mathrm{sv}}$ value was in the order of $10^{4}-10^{5} \mathrm{M}^{-1}$, suggesting a significant interaction of $\mathrm{Zn}$ ions with $\mathrm{L}$, which leads to the fluorescence quenching. The quenching pattern observed was then due to the formation of a non-fluorescent $\mathrm{Zn}-\mathrm{L}$ coordination complex (see Scheme 2). 


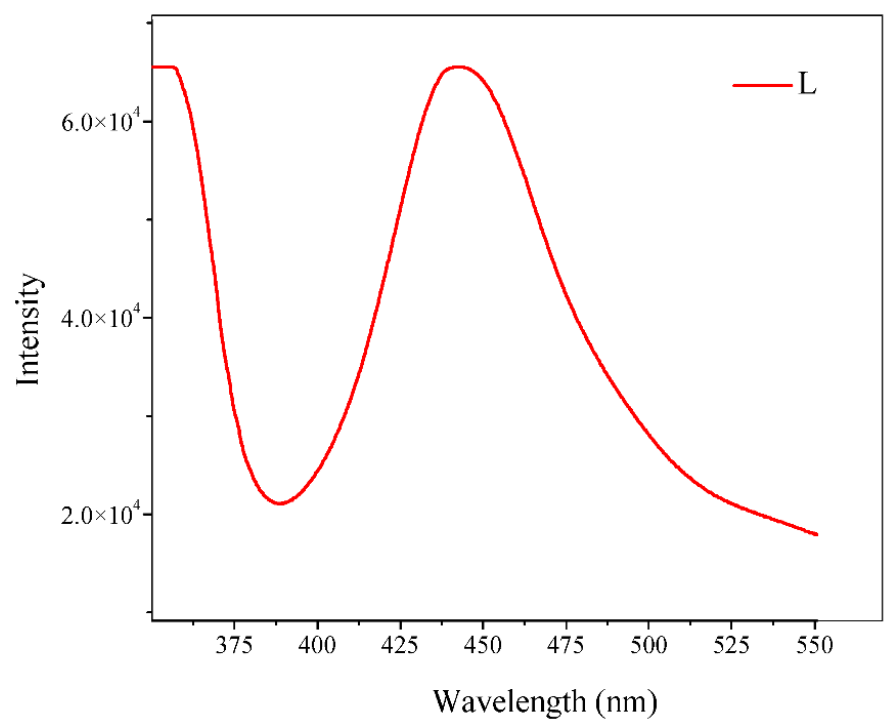

(a)

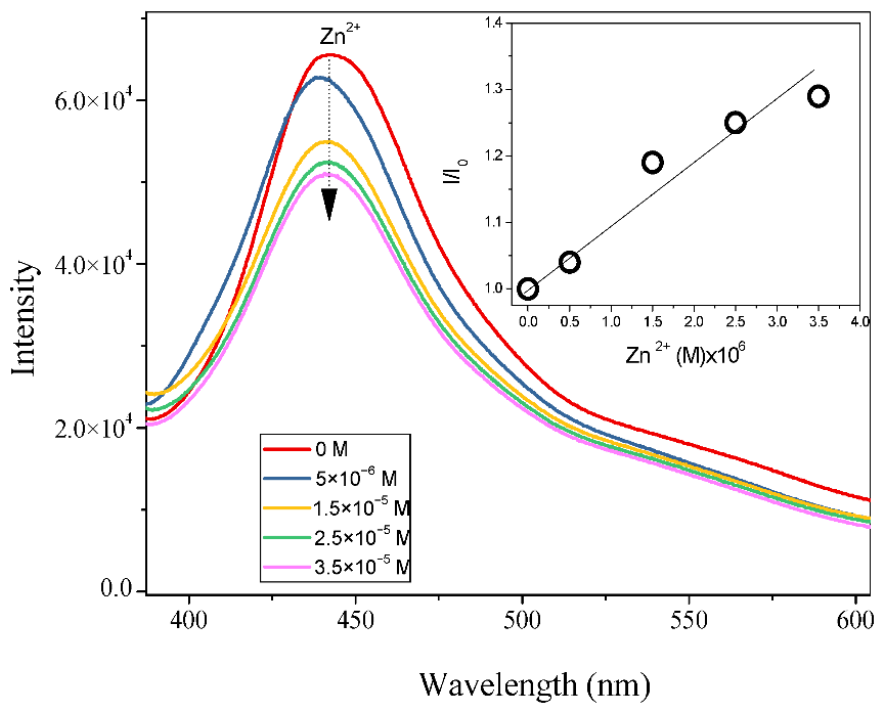

(b)

Figure 4. (a) Photoluminescence emission peak of the Schiff base ligand L; (b) variation in the photoluminescence peak at the addition of different $\mathrm{Zn}$ ions concentrations from 0 to $3.5 \times 10^{-5} \mathrm{M}$. Inset shows the fluorescence quenching Stern-Volmer plot with increasing concentration of $\mathrm{Zn}$ ions.

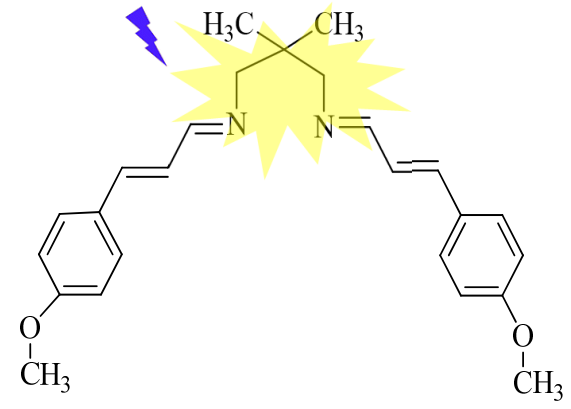

(a)

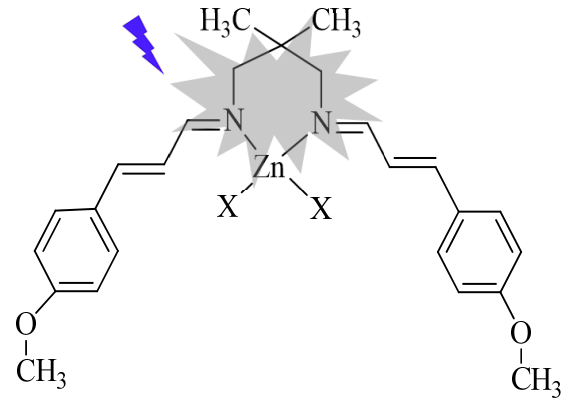

(b)

Scheme 2. Schematization of the fluorescent emission behavior for: (a) ligand L; (b) Zn-L coordination complex. Wavelength excitation is $340 \mathrm{~nm}$. 


\subsection{Electrochemical Studies}

Based on the promising coordination ability for $\mathrm{Zn}$ ions, the L ligand was used to modify a commercial screen-printed electrode for developing a simple electrochemical device for the electroanalytical determination of these ions. First, the electrochemical properties related to the modified sensors were evaluated by cyclic voltammetry $(\mathrm{CV})$. $\mathrm{CV}$ measurements were recorded in $1.0 \mathrm{mM}$ phosphate buffered saline (PBS) solution at $\mathrm{pH} 7.4$ as electrolyte and in the presence of the ferro/ferrocyanide $\left(\mathrm{Fe}(\mathrm{CN})_{6}{ }^{3-/ 4-}\right)$ redox couple. Cyclic voltammograms were recorded in $10 \mathrm{mM}\left(\mathrm{Fe}(\mathrm{CN})_{6}{ }^{3-/ 4-}\right)$ solution at a scan rate of $50 \mathrm{mV} \mathrm{s}^{-1}$. For all the bare and modified SPCEs, a pair of distinct, well-defined redox couple peaks were observed between -0.3 and $+1 \mathrm{~V}$ (Figure 5 ).

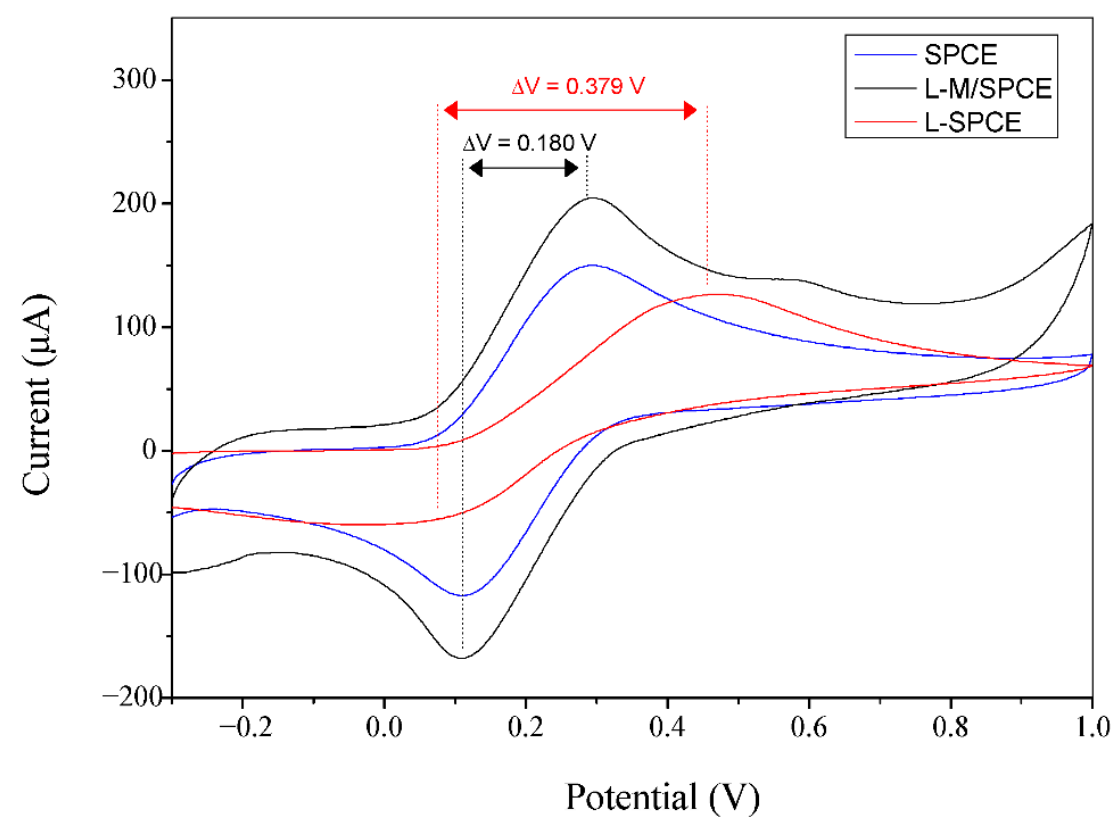

Figure 5. CV measurements of SPCE, L-SPCE and L-M/SPCE in PBS solution; CV of $10 \mathrm{mM}$ $\left(\mathrm{Fe}(\mathrm{CN})_{6}{ }^{3-/ 4-}\right)$ solution at a scan rate of $50 \mathrm{mV} \mathrm{s}^{-1}$.

On the bare SPCE, a pair of redox peaks with the peak-to-peak separation $(\triangle \mathrm{Ep})$ of $0.180 \mathrm{~V}$ was observed. On the L/SPCE, redox peaks are largely suppressed, likely due to the insulating layer formed after the Schiff base deposition on the working layer. Further, the $(\triangle \mathrm{Ep})$ was extended to 0.379 due to the presence of ligand $\mathrm{L}$, which limits the diffusion process. On the L-M/SPCE, a higher peak current was observed in comparison to SPCE and L/SPCE. The presence of the membrane restores the electrochemical properties of the L-M based electrode, which could be ascribed to the high ionic conductivity of the M membrane used together with the L ligand.

The effective electrochemical active surface area of the prepared electrode was also determined from these data based on the Randlese-Sevcik equation. The formula was employed to determine the active surface area of the SPCE and L-M/SPCE using the ferro/ferrocyanide as the redox probe:

$$
\mathrm{Ip}= \pm 0.4463 \mathrm{nFAC} \sqrt{ } \frac{\mathrm{nFvD}}{\mathrm{RT}}
$$

where Ip is the voltammetric current (A) using the forward peak of the electrochemical process, $\mathrm{n}=1$ is the number of electrons transferred in the electrochemical reaction, $\mathrm{F}=96485.3365 \mathrm{C} / \mathrm{mol}$ is the Faraday constant, $\mathrm{A}$ is the electrode surface area $\left(\mathrm{cm}^{2}\right)$, $\mathrm{C}=10^{-5} \mathrm{M} / \mathrm{cm}^{3}$ is the concentration of the redox probe, $\mathrm{v}=0.05 \mathrm{~V} / \mathrm{s}$ is the applied voltammetric scan rate, $\mathrm{D}=7.6 \times 10^{-6} \mathrm{~cm}^{2} / \mathrm{s}$ is the analytic diffusion coefficient, $\mathrm{R}=8.314 \mathrm{~J} / \mathrm{mol}$ is the universal gas constant and $\mathrm{T}=298.15 \mathrm{~K}$ is the Kelvin temperature. The increase in 
the effective electrochemical active surface area of L-M/SPCE was about $16 \%$ compared to the bare SPCE.

Further investigation of the electron transfer properties at the bare and modified electrodes was performed using electrochemical impedance spectroscopy (EIS). Here, the changes in the impedance and interface properties during the electrode surface modification procedure were measured and are shown in Figure 6.

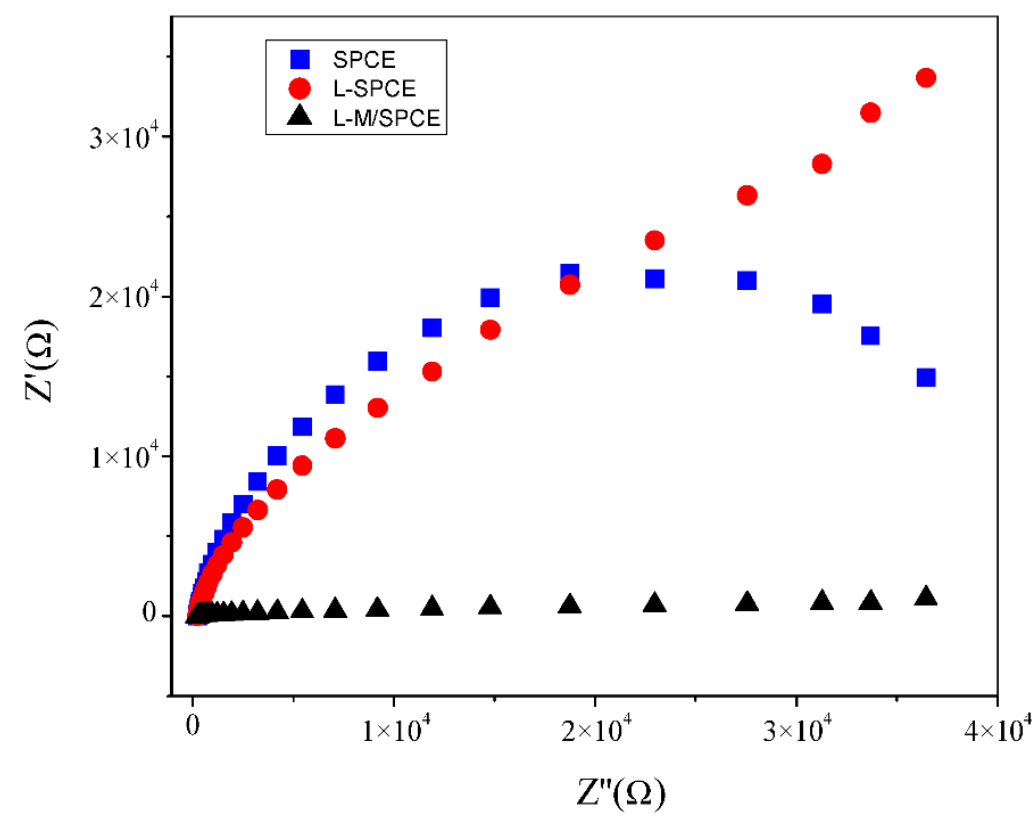

Figure 6. EIS of the fabricated sensors in $10 \mathrm{mM}\left(\mathrm{Fe}(\mathrm{CN})_{6}{ }^{3-/ 4-}\right)$ solution.

EIS experiments were carried out in a $10 \mathrm{mM}\left(\mathrm{Fe}(\mathrm{CN})_{6}{ }^{3-/ 4-}\right)$ solution over the $0.1-100,000 \mathrm{~Hz}$ range. Typically, impedance spectra consist of semi-circular and linear regions that represent electron transfer and diffusion processes, respectively. Electron transfer processes occur at higher frequencies, whereas diffusion processes occur at lower frequencies. The results reported highlight that the L-M layer causes a notable decrease in the impedance with respect to bare SPCE and L/SPCE, confirming the beneficial role of an ionic membrane used in cooperation with Schiff base ligand. These enhanced electrochemical properties encouraged us to investigate the developed L-M/SPCE as a sensor for the analytical determination of metal ions, in particular Zn (II).

\subsection{Electroanalytical Applications}

For the analytical application of the fabricated electrochemical sensors, several voltammetric methods can be applied [25]. To investigate the capabilities of bare and modified SPCE electrodes for the detection of Zn ions in distilled water, the LSV method was first applied. The curves shown in the graph in Figure 7a report the current of the L-M/SPCE sensor subjected to an increase in the potential from 0.25 to $0.90 \mathrm{~V}$ in the presence of different concentrations of $\mathrm{Zn}$ ions in solution. The registered current increases contemporaneously with the applied potential and concentrations of $\mathrm{Zn}$ ions. 


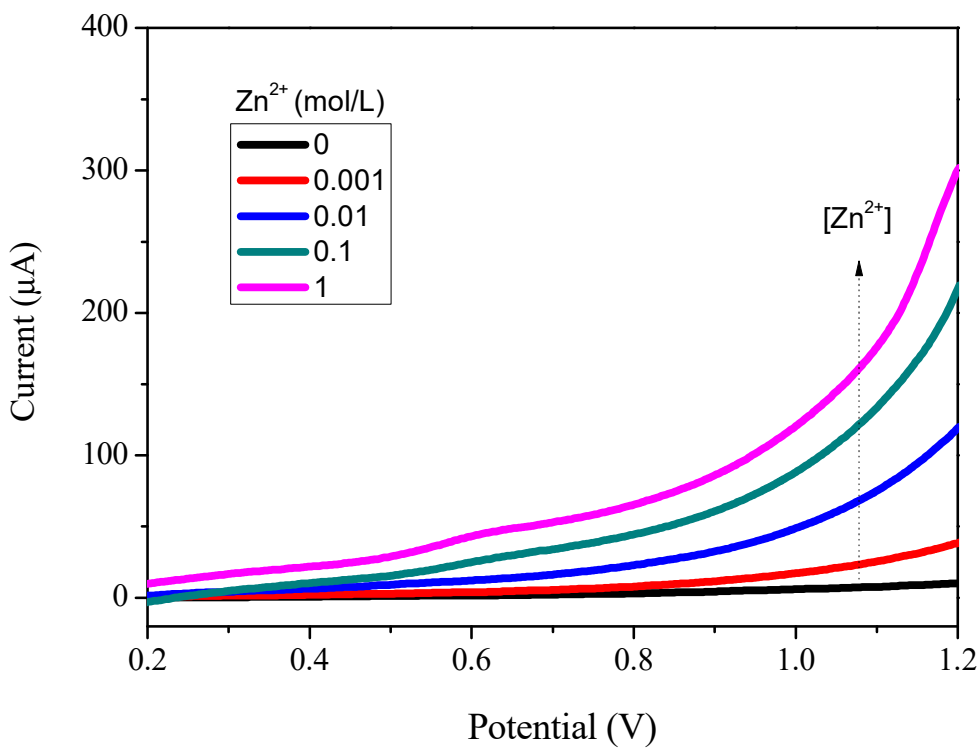

(a)

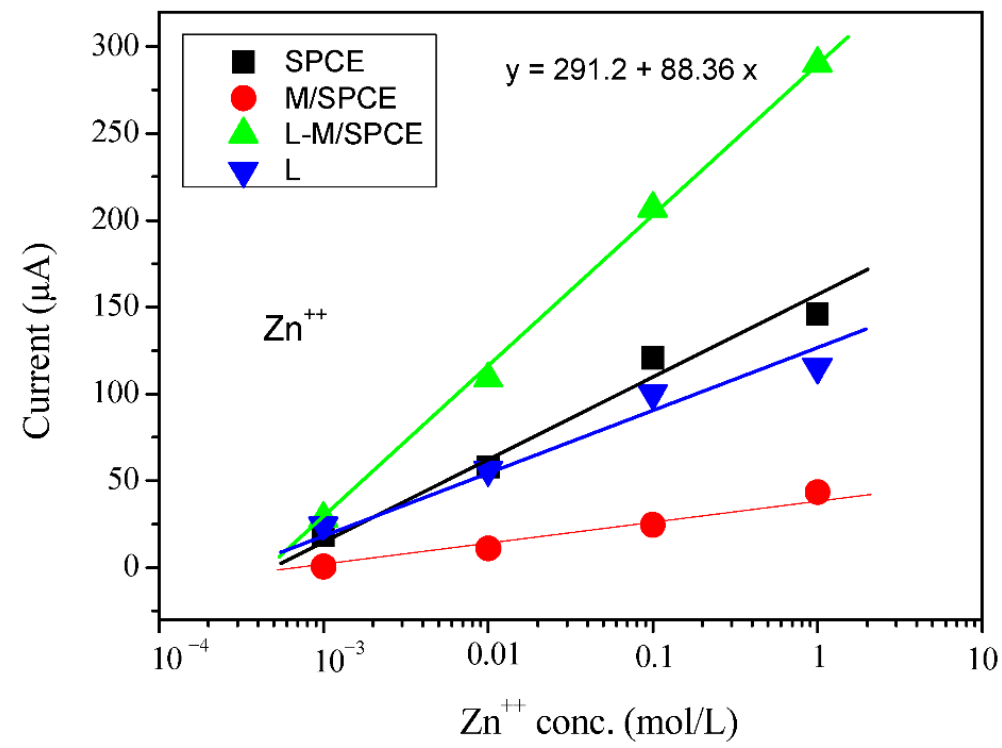

(b)

Figure 7. (a) I-V tests carried out on L-M modified SPCE in the presence of different concentrations of zinc ion. (b) Current registered at $1.2 \mathrm{~V}$ vs. concentration of $\mathrm{Zn}$ ions in solution for the various fabricated sensors.

Plotting the current registered at the potential of $1.2 \mathrm{~V}$, we observe a good linearity vs. zinc ions concentration in the range of $10^{-3}-1 \mathrm{M}$ (Figure $7 \mathrm{~b}$ ). From the statistical analysis applied, the equation found was $y=291.2+88.36 x$, and $R^{2}=0.99798$. In this figure are also reported the data collected in the same conditions for the bare SPCE, M/SPCE and L/SPCE sensors. A different response of the investigated sensor to $\mathrm{Zn}^{2+}$ is clearly noted. The response of the L-M/SPCE sensor was higher than the response of the other sensors tested.

Results from the LSV method demonstrate that the modification of the bare SPCE electrode with the combination of $\mathrm{L}$ as the ionophore and $\mathrm{M}$ as the ionic membrane contributes to the improved electrochemical detection of zinc ions compared to bare SPCE. As support for this, we present in Figure 8 data obtained with $\mathrm{K}$ ions. This ion was chosen because it is not coordinated at the modified L-M/SPCE electrode. We can observe on bare SPCE and L-M-SPCE sensors a different response in solutions containing $\mathrm{K}$ ions 
compared to the behavior reported in Figure 7 in the presence of $\mathrm{Zn}$ ions, confirming that the characteristics of the L-M/SPCE sensor are linked to the coordination ability towards $\mathrm{Zn}$ ions.

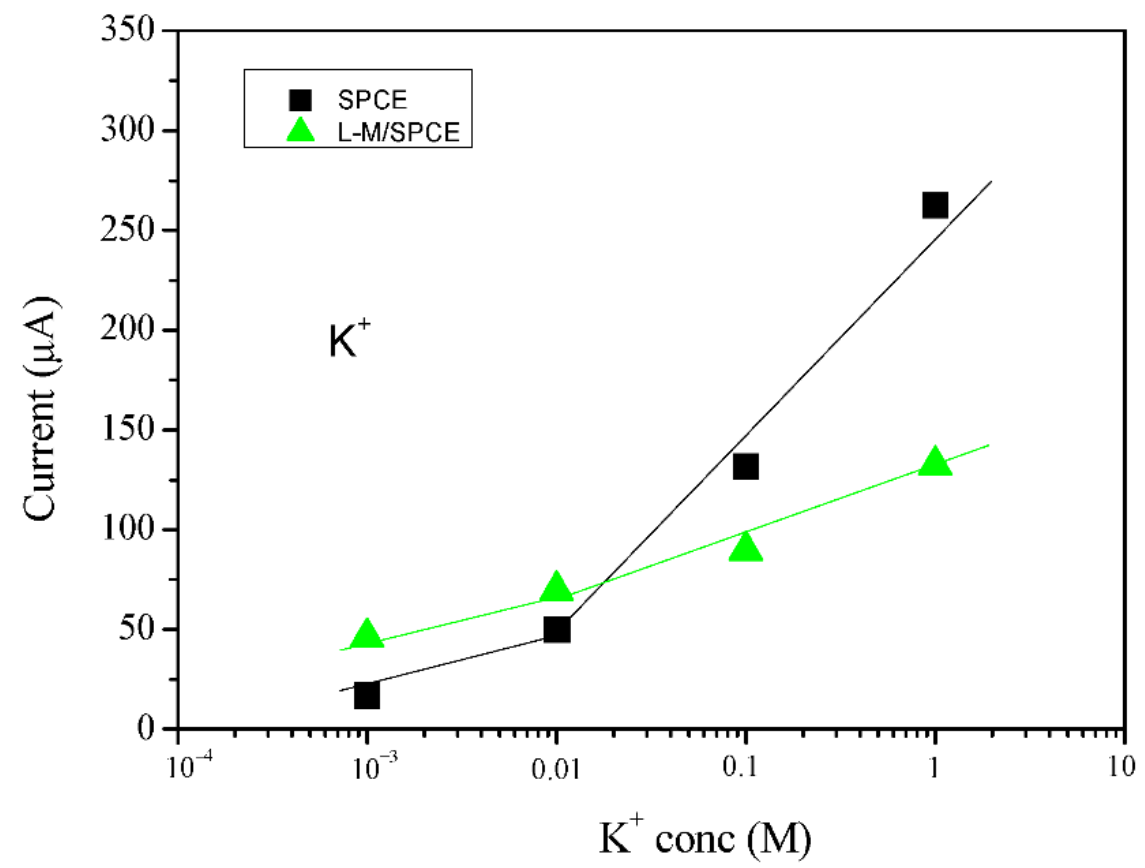

Figure 8. Current registered on bare SPCE and L-M/SPCE sensors at $1.2 \mathrm{~V}$ vs. concentration of K ions in solution.

Potentiometry is one of the most commonly developed electrochemical methods, and is based on the measurement of a potential difference when the target ionic species in an aqueous phase complex with target selective ionophores present in an organic membrane [26]. Potentiometric sensing can be an attractive alternative to the existing electrochemical analytical tools due to its simplicity and fast responses [27]. Figure 8 shows the selective response of the bare SPCE and L-M/SPCE sensors to zinc ion addition. It can be observed that the response of the modified electrode is highly amplified with respect to the bare electrode with a sensitivity of $50.1 \mathrm{mV} / \mathrm{dec}$.

The dynamic response time of the L-M/SPCE sensor was also evaluated. The inset in Figure 9 shows the potential variation of the sensor to a step change in the concentration of $\mathrm{Zn}^{2+}$ ion. A fast response was noted; indeed, the time required for the $\mathrm{Zn}^{2+}$ sensor to reach the new potential value was about $10 \mathrm{~s}$.

Aqueous solutions of both monovalent and divalent cations were also added, measuring the potential changes for each addition, for evaluating the selectivity of the sensor. The concentration was kept the same for all cations $\left(5.5 \times 10^{-5} \mathrm{~mol} / \mathrm{L}\right)$ and the additions were made directly to the solution, which was kept under mechanical stirring. According to the potentiometric results, the sensitivity towards $\mathrm{Zn}$ ions of the proposed sensor is much higher compared to other ions, thus evidencing its good selectivity (Figure 10). Regarding the LSV method, the high selectivity registered with the potentiometric method is due to the high affinity of the L-M/SPCE sensor for Zn compared to the other metal ions. 


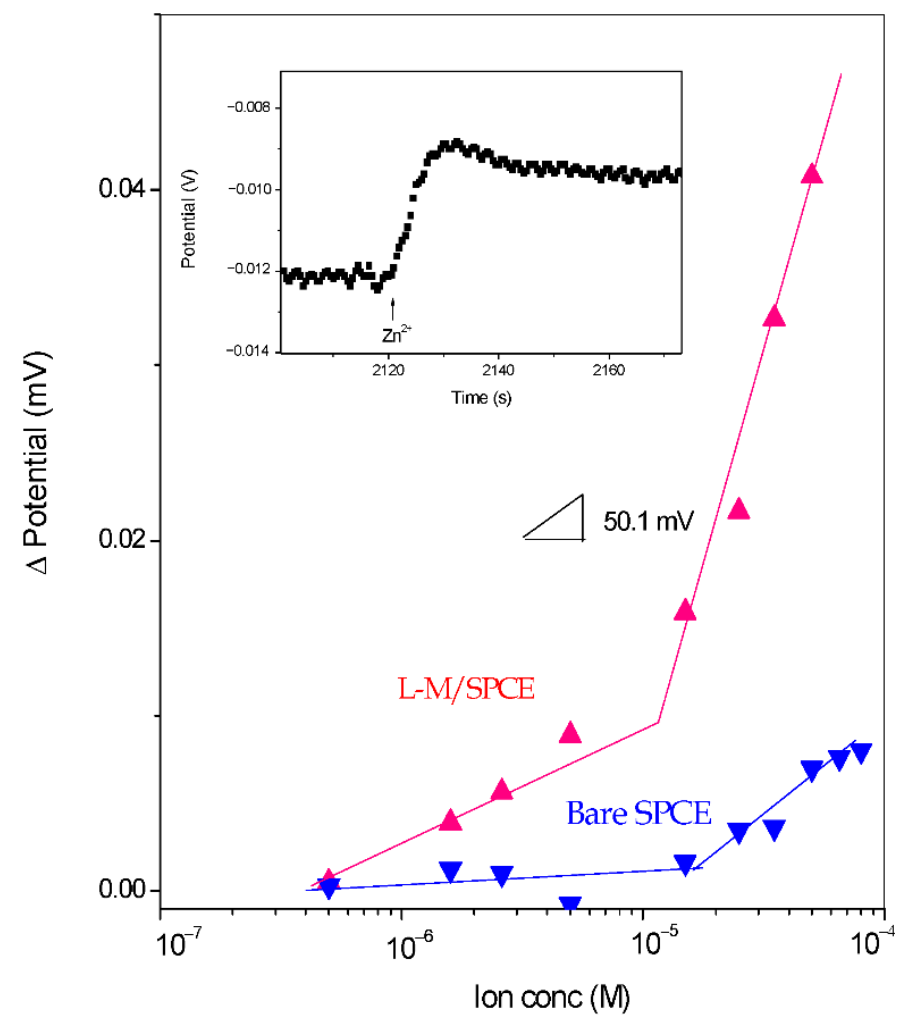

Figure 9. Calibration curves for the SPCE and L-M/SPCE sensors to different concentrations of $\mathrm{Zn}$ ions. Dynamic response of the L-M/SPCE sensor for a step change in the concentration of $\mathrm{Zn}^{2+}$ ion.

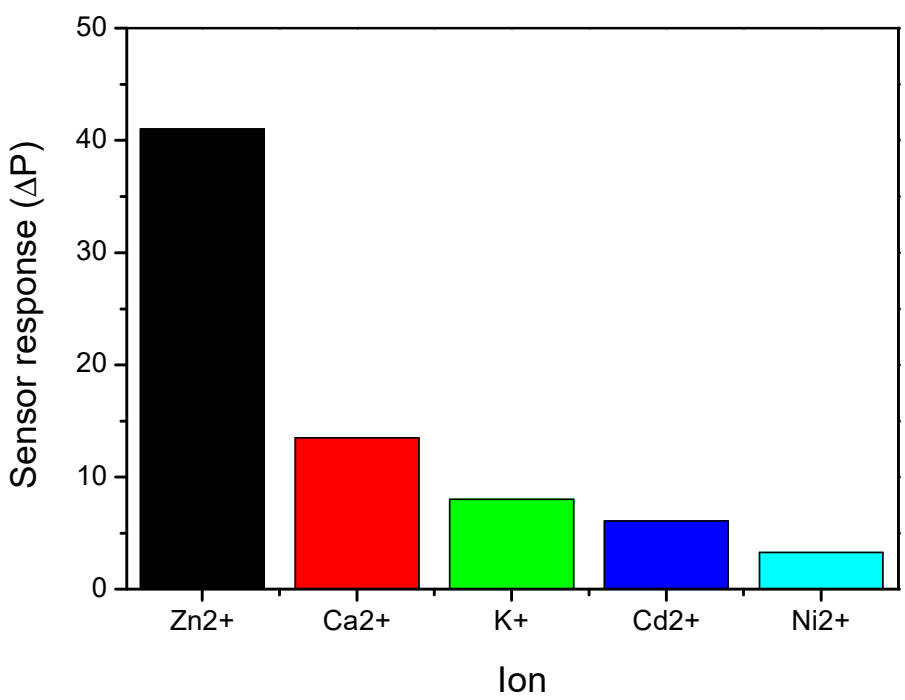

Figure 10. Response of the L-M/SPCE sensor to different ions. The concentration of the ions is equal to $5.5 \times 10^{-5} \mathrm{~mol} / \mathrm{L}$.

To explain the observed behavior, we believe that the sensor response is generated by: (i) the electric double layer at the interface between the solution and (ii) the L-M membrane and the ion transfer from the solution to the L-M membrane. That is, the observed response is the result of the combined effects of the ionic conductivity of the ion solution and the resistance at the electrode/ion solution interface. At a certain concentration of $\mathrm{Zn}^{2+}$, the first contribution is constant, so the electrode/ion solution interface resistance is the dominant factor, and this agrees with the different EIS spectra obtained on the various electrodes. However, the highest response of the L-M/SPCE potentiometric sensor can be explained 
by the preferential adsorption of $\mathrm{Zn}^{2+}$ onto the electrode surface. Indeed, as demonstrated by a photoluminescence study, nitrogen as a supplier of donor atoms in the L ligand acts as a strong coordination site for binding zinc, enhancing the electrochemical properties of the L-M/SPCE membrane towards the detection of zinc ions.

Table shows a comparison of the $\mathrm{Zn}^{2+}$ sensing performances of our electrochemical sensor with others reported in the literature. As is well known, electrochemical techniques based mainly on stripping voltammetry (ASV) methods have been widely reported in the scientific literature for $\mathrm{Zn}$ ion detection because of their high sensitivity [15-18]. These electrochemical sensors undoubtedly have high performance, but the presence of some toxic components (especially in the mercury-based electrodes) limits their acceptance in wide-scale routine analysis. Therefore, the potentiometric Zn sensor based on the novel synthesized Schiff base L may be a strong competitor, with similar or better electrochemical properties, compared to sensors with other Schiff bases or based on different electrode sensing materials proposed to date (see refs. [28-31] in Table 1). In addition to compliance with safety regulations, this sensor has the advantage of enabling a simple, cost-effective, and easy preparation process.

Table 1. Comparison of the $\mathrm{Zn}^{2+}$ sensing performances of sensors reported in the literature.

\begin{tabular}{|c|c|c|c|}
\hline Sensing Material & Linear Range & Limit of Detection (LOD) & Ref. \\
\hline Ionophore (SMS-3) Schiff base moiety modified SPCE & 0.47 to $5.56 \mu \mathrm{M}$ & $0.92 \mu \mathrm{M}$ & [28] \\
\hline Aminoacid Schiff base modified GCE & 10 to $150 \mu \mathrm{M}$ & - & [29] \\
\hline 3-D printed carbon nanofiber-graphite-polystyrene & $12.7 \mu \mathrm{g} / \mathrm{L}$ to $450 \mu \mathrm{g} / \mathrm{L}$ & $8.6 \mu \mathrm{g} / \mathrm{L}$ & {$[30]$} \\
\hline Screen printed bismuth oxide & 75 to $600 \mathrm{mg} / \mathrm{L}$ & $33 \mathrm{mg} / \mathrm{L}$ & [31] \\
\hline Coumarin-based fluorescent sensor & $100 \mathrm{pM}$ to $1 \mathrm{mM}$ & $3 \mu \mathrm{M}$ & {$[32]$} \\
\hline L-SPCE & $1 \mu \mathrm{M}$ to $100 \mathrm{mM}$ & $3.5 \mu \mathrm{M}$ & This work \\
\hline
\end{tabular}

The issue of selectivity is also of particular importance for the practical applicability of these sensors. Most metal ions, in particular $\mathrm{Ca}^{2+}$, are usually present in high concentrations in water samples and can interfere in the detection of zinc ions. Very selective modified electrodes with a Schiff base, such as SMS-3, having high affinity toward Zn ions, have been proposed [28]. Other Schiff bases have been reported in the literature for developing high-performance electrochemical/fluorescent sensors for $\mathrm{Zn}$ ions, but the selectivity issue is not addressed (see refs. [29,32]).

Schiff bases are also used as fluorescent probes for the detection of zinc ions [32-34]. Obviously, this technique displays better performance regarding the selectivity issue, but needs more complicated instruments than the electrochemical approach. Instead, the proposed electrochemical sensor for $\mathrm{Zn}$ ions is of low cost and simple to use. In the case of the presence of high concentrations of interferent ions such as $\mathrm{Ca}^{2+}$, a selective preconcentration step must be applied to overcome this problem [35]. In contrast, in the determination of $\mathrm{Zn}$ in foods and pharmaceutical tablets, the preconcentration step is not necessary [36,37].

\section{Conclusions}

In conclusion, the novel synthesized Schiff base L was found to be suitable as a sensing material for the detection of $\mathrm{Zn}$ ions in water. Photoluminescence studies showed that $\mathrm{L}$ displays a fluorescence turn-off in the presence of Zn2+ due to its high coordination ability for this ion. A simple electrochemical sensor was then fabricated by modification of SPCEs with $\mathrm{L}$ as the recognition layer, and showed a micromolar detection limit and good linearity with a high sensitivity of $\sim 50.1 \mathrm{mV} / \mathrm{dec}$ for sensing $\mathrm{Zn}^{+2}$ ions. A fast response time of about $10 \mathrm{~s}$ with good selectivity to some common interferent ions was also demonstrated. Further, these sensors are easy to fabricate and are intrinsically safe as compared to the traditionally used mercury-based electrodes. 
Based on the knowledge acquired in this first study, our future work will focus on developing novel probes for heavy metal ions and the fabrication of electrochemical sensors based on these receptors.

Author Contributions: Conceptualization, M.M., C.E., D.I. and G.N.; methodology, C.E and G.N.; data curation, V.B., A.F. and Z.A.; investigation, V.B., A.F. and Z.A., writing-original draft preparation, C.E., M.M., G.N., V.B., A.F., D.I. and Z.A.; writing-review and editing, C.E. and G.N.; supervision, C.E. and G.N.; All authors have read and agreed to the published version of the manuscript.

Funding: This article was funded by MUR under the framework of the project PON "Ricerca e Innovazione" 2014-2020-Azione II, Progetto "TETI-Tecnologie innovative per il controllo, il monitoraggio e la sicurezza in mare".

Institutional Review Board Statement: Not applicable.

Informed Consent Statement: Not applicable.

Data Availability Statement: Not applicable.

Conflicts of Interest: The authors declare no conflict of interest.

\section{References}

1. Furniss, B.S.; Hannaford, A.J.; Smith, P.W.J.; Tatchell, A.R. Vogel's Textbook of Practical Organic Chemistry, 5th ed.; Longman Scientific \& Technical: Essex, UK, 1989.

2. Santhoshkumar, S.; Velmurugan, K.; Prabhu, J.; Radhakrishnan, G.; Nandhakumar, R. A naphthalene derived Schiff base as a selective fluorescent probe for Fe ${ }^{2+}$. Inorg. Chim. Acta 2016, 439, 1-7. [CrossRef]

3. Kaur, N.; Kaur, B. Colorimetric and fluorescent multi-ion recognition by Anthracene appended di-Schiff base chemosensor. Inorg. Chem. Commun. 2020, 121, 108239. [CrossRef]

4. Durai, W.A.; Ramu, A.; Dhakshinamoorthy, A. A chromogenic and fluorescence turn-on sensor for the selective and sensitive recognition of $\mathrm{Al}^{3+}$ ions-A new approach by Schiff base derivative as probe. Inorg. Chem. Commun. 2020, 121, 108191. [CrossRef]

5. Ghosh, S.; Singharoy, D.; Konar, S.; Naskar, J.P.; Bhattacharya, S.C. Solvatochromic behavior of a pyrene-pyrimidine-based Schiff base and detection of heavy metal ions in aqueous media. J. Coord. Chem. 2021, 74, 1272-1283. [CrossRef]

6. Mohammed, M.Q.; Ismail, H.K.; Alesary, H.; Barton, S.J. Use of a Schiff base-modified conducting polymer electrode for electrochemical assay of $\mathrm{Cd}(\mathrm{II})$ and $\mathrm{Pb}(\mathrm{II})$ ions by square wave voltammetry. Chem. Pap. 2021, 28, 1-15. [CrossRef]

7. Forzani, E.S.; Zhang, H.; Chen, W.; Tao, N. Detection of Heavy Metal Ions in Drinking Water Using a High-Resolution Differential Surface Plasmon Resonance Sensors. Environ. Sci. Technol. 2005, 39, 257-1262. [CrossRef]

8. Dzianová, P.; Asai, S.; Chrudinová, M.; Kosinová, L.; Potalitsyn, P.; Šácha, P.; Hadravová, R.; Selicharová, I.; Kříž, J.; Turkenburg, J.P.; et al. The efficiency of insulin production and its content in insulin-expressing model $\beta$-cells correlate with their $\mathrm{Zn}^{2+}$ levels. Open Biol. 2020, 10, 200137. [CrossRef]

9. Kambe, T.; Matsunaga, M.; Takeda, T.A. Understanding the contribution of zinc transporters in the function of the early secretory pathway. Int. J. Mol. Sci. 2017, 18, 2179. [CrossRef]

10. Kambe, T.; Taylor, K.M.; Fu, D. Zinc transporters and their functional integration in mammalian cells. J. Biol. Chem. 2021, 296, 100320. [CrossRef]

11. Hsieh, W.H.; Wan, C.F.; Liao, D.J.; Wu, A.T. A turn-on Schiff base fluorescence sensor for zinc ion. Tetrahedron Lett. 2012, 53, 5848-5851. [CrossRef]

12. Lavado, L.K.; Zhang, M.H.; Patel, K.; Khan, S.; Patel, U.K. Biometals as Potential Predictors of the Neurodegenerative Decline in Alzheimer's Disease. Cureus 2019, 11, 557. [CrossRef] [PubMed]

13. Mezzaroba, L.; Frizon Alfieri, D.; Colado Simao, A.N.; Vissoci Reiche, E.M. The role of zinc, copper, manganese and iron in neurodegenerative diseases. Neurotoxicology 2019, 74, 230-241. [CrossRef] [PubMed]

14. Bressi, V.; Ferlazzo, A.; Iannazzo, D.; Espro, C. Graphene Quantum Dots by Eco-Friendly Green Synthesis for Electrochemical Sensing: Recent Advances and Future Perspectives. Nanomaterials 2021, 11, 1120. [CrossRef] [PubMed]

15. Israel, Y.; Ofir, T.; Rezek, J. Determination of trace impurities in high-purity reagents by mercury thin-film anodic-stripping voltammetry. Microchim. Acta 1978, 69, 151-163. [CrossRef]

16. Martinotti, W.; Queirazza, G.; Guarinoni, A.; Mori, G. In-flow speciation of copper, zinc, lead and cadmium in fresh waters by square wave anodic stripping voltammetry Part II. Optimization of measurement step. Anal. Chim. Acta 1995, 305, 183-191. [CrossRef]

17. Lu, T.; Huang, J.; Sun, I. Perfluorinated anion-exchange polymer mercury film electrode for anodic stripping voltammetric determination of zinc (II): Effect of model organic compounds. Anal. Chim. Acta 2002, 454, 93-100. [CrossRef]

18. De Oliveira, M.F.; Saczk, A.A.; Okumura, L.L.; Fernandes, A.P.; De Moraes, M.; Stradiotto, N.R. Simultaneous determination of zinc, copper, lead, and cadmium in fuel ethanol by anodic stripping voltammetry using a glassy carbon-mercury-film electrode. Anal. Bioanal. Chem. 2004, 380, 135-140. [CrossRef] 
19. Akbari, Z.; Montazerozohori, M.; Bruno, G.; Moulaee, K.; Neri, G. Development of a novel electrochemical nitrite sensor based on Zn-Schiff base complexes. Appl. Organomet. Chem. 2022. [CrossRef]

20. Faridbod, F.; Ganjali, M.R.; Dinarvand, R.; Norouzi, P. Ion recognition: Application of symmetric and asymmetric Schiff bases and their complexes for the fabrication of cationic and anionic membrane sensors to determine ions in real samples. Comb. Chem. High. Throughput Screen. 2007, 10, 527-546. [CrossRef]

21. Saleh, S.M.; Ali, R.; Ali, I.A. A novel, highly sensitive, selective, reversible and turn-on chemi-sensor based on Schiff base for rapid detection of $\mathrm{Cu}$ (II). Spectrochim. Acta A Mol. Biomol. Spectrosc. 2017, 183, 225-231. [CrossRef]

22. Lee, H.; Lee, H.S.; Reibenspies, J.; Hancock, R.D. Mechanism of "turn-on" fluorescent sensors for mercury (II) in solution and its implications for ligand design. Inorg. Chem. 2012, 51, 10904-10915. [CrossRef]

23. Deems, J.C.; Reibenspies, J.H.; Lee, H.S.; Hancock, R.D. Strategies for a fluorescent sensor with receptor and fluorophore designed for the recognition of heavy metal ions. Inorg. Chim. Acta 2020, 499, 119181. [CrossRef]

24. Yu, Y.; Wang, Y.; Yan, H.; Lu, J.; Liu, H.; Li, Y.; Wang, S.; Li, D.; Dou, J.; Yang, L.; et al. Multiresponsive luminescent sensitivities of a $3 \mathrm{D} \mathrm{Cd}-\mathrm{CP}$ with visual turn-on and ratiometric sensing toward $\mathrm{Al}^{3+}$ and $\mathrm{Cr}^{3+}$ as well as turn-off sensing toward $\mathrm{Fe}^{3+}$. Inorg. Chem. 2020, 59, 3828-3837. [CrossRef]

25. Lu, Y.; Liang, X.; Niyungeko, C.; Zhou, J.; Xu, J.; Tian, G. A review of the identification and detection of heavy metal ions in the environment by voltammetry. Talanta 2018, 178, 324-338. [CrossRef]

26. Abd El-Rahman, M.K.; Mazzone, G.; Mahmoud, A.M.; Sicilia, E.; Shoeib, T. Novel choline selective electrochemical membrane sensor with application in milk powders and infant formulas. Talanta 2021, 221, 121409. [CrossRef]

27. Dehabadi, M.; Legin, E.; Legin, A.; Yaghmaei, S.; Nechaev, S.; Babain, V.; Kirsanov, D. Developing potentiometric sensors for scandium. Sens. Actuators B Chem. 2021, 348, 130699. [CrossRef]

28. Rana, S.; Mittal, S.K.; Kaur, K.; Banks, C.K. Pseudo Cavity of Schiff Base Ionophore Incorporated in Screen Printed Electrode for Sensing of Zn (II). J. Electrochem. Soc. 2019, 166, B464. [CrossRef]

29. Kavitha, A.; Easwaramoorthy, D. Aminoacid Schiff base Fabricated Glassy carbon Electrode for Efficient Sensing of Zinc, Copper, Mercury ions in Water. IOP Conf. Ser. Mater. Sci. Eng. 2020, 988, 012042. [CrossRef]

30. Honeychurch, K.C.; Rymansai, Z.; Iravani, P. Anodic stripping voltammetric determination of zinc at a 3-D printed carbon nanofiber-graphite-polystyrene electrode using a carbon pseudo-reference electrode. Sens. Actuators B Chem. 2018, 267, 476-482. [CrossRef]

31. Khairy, M.; Kadara, R.O.; Kampouris, D.K.; Banks, C.E. Disposable Bismuth Oxide Screen Printed Electrodes for the Sensing of Zinc in Seawater. Electroanalysis 2010, 22, 1455-1459. [CrossRef]

32. Narakathu, B.B.; Abebe, F.A.; Eribal, C.S.; Sinn, E.; Atashbar, M.Z. Detection of $\mathrm{Zn}^{2+}$ Ions Using a Novel Chemosensor Based on Coumarin Schiff-base Derivatives by Electrochemical and Fluorescence Spectroscopy. In Proceedings of the 14th International Meeting on Chemical Sensors 2012, Nuremberg, Germany, 20-23 May 2012.

33. Hosseini, M.; Vaezi, Z.; Reza Ganjali, M.; Faridbod, F.; Dehghan Abkenar, S.; Alizadeh, K.; Salavati-Niasari, M. Fluorescence "turn-on" chemosensor for the selective detection of zinc ion based on Schiff-base derivative. Spectrochim. Acta A Mol. Biomol. Spectrosc. 2010, 75, 978-982. [CrossRef] [PubMed]

34. Kaur, P.; Singh, R.; Kaur, P. Dual role of silatranized Schiff base as a fluorimetric probe and a linker to functionalize graphene oxide for the selective detection and adsorption of zinc ions. Inorg. Chim. Acta 2020, 512, 119859. [CrossRef]

35. Saçmac1, S. Selective back-extraction and preconcentration of zinc (II) from metal-1,3,5-triketone extracts prior to its determination by flame atomic absorption spectrometry. Int. J. Environ. Anal. Chem. 2012, 92, 1626-1637. [CrossRef]

36. Wang, J.; Dewald, H.D. Determination of trace elements in pharmaceutical tablets using anodic stripping voltammetry. Anal. Lett. 1983, 16, 925-940. [CrossRef]

37. Lutka, A.; Kokot, Z.; Powidzka, H. Validation of electrochemical determination of zinc in selected pharmaceutical preparations. Acta Pol. Pharm. 2004, 61, 243-247. 